\title{
Suboptimal infant and young child feeding practices among internally displaced persons during conflict in eastern Ukraine
}

\author{
Aimee Summers ${ }^{1,2, *}$ and Oleg O Bilukha ${ }^{2}$ \\ ${ }^{1}$ Epidemic Intelligence Service, Centers for Disease Control and Prevention, Atlanta, GA, USA: ${ }^{2}$ Emergency \\ Response and Recovery Branch, Division of Global Health Protection, Center for Global Health, Centers for Disease \\ Control and Prevention, 1600 Clifton Road, Mailstop E-22, Atlanta, GA 30329, USA
}

Submitted 15 November 2016: Final revision received 19 0ctober 2017: Accepted 20 0ctober 2017: First published online 22 December 2017

\begin{abstract}
Objective: To determine current status, areas for improvement and effect of conflict on infant and young child feeding (IYCF) practices among internally displaced persons (IDP) in eastern Ukraine.

Design: Cross-sectional household survey, June 2015.

Setting: Kharkiv, Dnipropetrovsk and Zaporizhia oblasts (Ukrainian administrative divisions) bordering conflict area in Ukraine.

Subjects: Randomly selected IDP households with children aged $<2$ years registered with local non-governmental organizations. Questions based on the WHO IYCF assessment questionnaire were asked for 477 children. Mid-upper arm circumference was measured in 411 children aged 6-23 months.

Results: Exclusive breast-feeding prevalence for infants aged $<6$ months was $25 \cdot 8$ (95\% CI 15.8, 38.0)\%. Percentage of mothers continuing breast-feeding when their child was aged 1 and 2 years was 53.5 (95\% CI 43.2, 63.6) \% and $20 \cdot 6$ (95\% CI 11.5, $32.7) \%$, respectively. Bottle-feeding was common for children aged $<2$ years $(68.1 \%$; 95\% CI 63.7, 72.3\%). Almost all infants aged 6-8 months received solid foods (98.6\%; 95\% CI 88.5, 99.9\%). Mothers who discontinued breast-feeding before their infant was 6 months old more often listed stress related to conflict as their primary reason for discontinuation (45.7\%) compared with mothers who discontinued breast-feeding when their child was aged 6-23 months $(14.3 \% ; P<0 \cdot 0001)$.

Conclusions: To mitigate the effects of conflict and improve child health, humanitarian action is needed focused on helping mothers cope with stress related to conflict and displacement while supporting women to adhere to recommended IYCF practices if possible and providing appropriate support to women when adherence is not feasible.
\end{abstract}

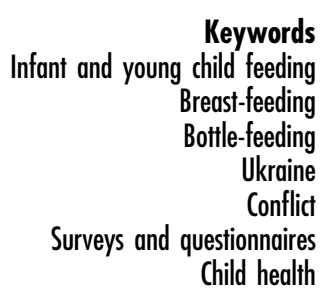

Appropriate infant and young child feeding (IYCF) practices have a large impact on child survival. Optimum breast-feeding practices alone could prevent an estimated 1.4 million deaths of children under 5 years of age worldwide $^{(1)}$. Specifically, exclusive breast-feeding until 6 months of age and continued breast-feeding up to 1 year of age have the greatest impact on reducing child mortality and prevent many deaths from diarrhoea, pneumonia and malnutrition $^{(1-4)}$. Furthermore, early initiation of breastfeeding prevents neonatal morbidity and mortality ${ }^{(5-7)}$. In addition to lower mortality from infection and malnutrition, breast-fed children also have a lower risk of dying from sudden infant death syndrome compared with children who are not breast-fed ${ }^{(1,8-10)}$

IYCF practices beyond breast-feeding also have a large impact on reducing child mortality. For instance, introducing complementary foods at 6 months of age is the third leading child health intervention in preventing child deaths ${ }^{(4)}$. Due to the evidence of child health benefits, the WHO and UNICEF recommend early initiation of breast-feeding within the first hour of birth, exclusive breast-feeding for the first 6 months of life, continued breast-feeding until 2 years of age, and timely introduction of nutritious complementary foods at 6 months of age ${ }^{(11)}$.

Despite these recommendations, many women, including those in high- and middle-income countries, do not follow the recommended IYCF practices. For example, only twothirds of infants in the USA are breast-fed within an hour of birth and less than a third of infants are exclusively breastfed until 6 months of age or are continuing to be breast-fed until 1 year of age, according to national surveys conducted by the Centers for Disease Control and Prevention (CDC) ${ }^{(12)}$. 
These findings are similar to those from middle-income countries in Eastern Europe bordering Ukraine, including Belarus, where in 2012 only about half of infants were breast-fed within the first hour of birth, one-fifth of infants were exclusively breast-fed until 6 months of age and less than one-third of infants continued to be breast-fed at 1 year of age according to Multiple-Indicator Cluster Survey (MICS) data $^{(13)}$. IYCF practices were similarly poor in eastern Ukraine. In 2012 the Ukrainian MICS found that only $62 \%$ of infants in the eastern region of Ukraine were breast-fed within an hour of birth and $21 \%$ exclusively breast-fed until 6 months of age ${ }^{(14)}$.

Prior to the beginning of the conflict in February 2014, Ukraine was considered a stable, middle-income country. Hostilities in the eastern oblasts (administrative divisions of Ukraine) of Donetsk and Luhansk began in June 2014. The conflict has caused political and financial instability and mass displacement. As of June 2015, there were a total of 1.4 million internally displaced persons (IDP) and over 5 million people affected by the conflict ${ }^{(15)}$. At that time, the majority of IDP lived in Donetsk and Luhansk oblasts (conflict zone) and in Kharkiv, Dnipropetrovsk and Zaporizhia oblasts bordering the conflict zone. The influence of this conflict on IYCF practices among the affected population was unknown, but important to consider. Complex humanitarian emergencies can lead to suboptimal hygiene and health-care practices, especially considering that overcrowding is common as IDP move into collective centres and homes of friends and relatives ${ }^{(16)}$. Furthermore, nutritious complementary foods may be unavailable and water sources may be compromised during complex humanitarian emergencies ${ }^{(17)}$. This can lead to a high risk of diarrhoea and infections, making optimal IYCF practices such as exclusive breast-feeding in infants until 6 months of age even more essential ${ }^{(16)}$. In addition, it is important that suboptimal feeding practices be identified, managed and supported appropriately if approaches such as artificial feeding are warranted. Given Ukraine's suboptimal pre-crisis IYCF practices, families with infants and young children affected by the conflict were of particular concern. The present study aimed to describe the current status, areas for improvement and effect of conflict on IYCF practices of IDP in Kharkiv, Dnipropetrovsk and Zaporizhia oblasts bordering the conflict zone.

\section{Methods}

We conducted a cross-sectional household survey among IDP households with children less than 2 years of age residing in Kharkiv, Dnipropetrovsk and Zaporizhia oblasts. The total sample size of 474 children was determined based on an expected $50 \%$ prevalence of current breast-feeding and a $\pm 4.5 \%$ precision $^{(14)}$. Oblast-specific sample sizes, allocated based on the relative numbers of IDP living in each oblast, were 230, 130 and 114 children from Kharkiv, Dnipropetrovsk and Zaporizhia, respectively.
We obtained lists of registered IDP families with infants and young children from humanitarian aid agencies to create the sampling frame. Lists were checked for duplicates and merged. A household was defined as persons living under the same roof who were registered together to receive assistance. The following criteria were used to identify IDP households eligible for the study: (i) household was included in at least one humanitarian agency list received; (ii) a working telephone number was provided on the registration list and a household could be reached by telephone; (iii) children less than 2 years old were living in the household; (iv) household was residing in Kharkiv, Dnipropetrovsk or Zaporizhia oblast at the time of the survey; and (v) the mother/caregiver consented to participate.

We independently selected households for each oblast. Lists were randomized and households were contacted in that random order via telephone until the required number of consenting households was reached. During the initial contact, we verified the child's age and whether the household was residing in the survey area. If the household did not meet the inclusion criteria or a household could not be reached after three call attempts on the day of the scheduled survey team visit, that household was removed from the list and the next household on the list was called. For households meeting the inclusion criteria during telephone screening, an in-person interview visit was scheduled. All children less than 2 years of age present in the household during the in-person interview were included in the survey.

The survey included questions about the child (age, sex), mother (age, education, total number of children) and household (current location, living situation, permanent residence before displacement, length of displacement, number of people living in the household, total number of children less than 2 years of age living in the household, sex of the head of household, current household employment and whether the household received humanitarian assistance). Questions on IYCF practices, derived from the standard WHO IYCF questionnaire, were also included ${ }^{(18)}$. The questionnaire was translated into Russian and the accuracy of the translation was verified by Russian-speaking CDC staff.

Questionnaires were administered to the child's mother, unless she was unavailable. If the mother was unavailable, the questionnaire was administered to a second caregiver with knowledge of the child's feeding practices. Midupper arm circumference (MUAC) was measured following standard procedures in each child aged 6-23 months. MUAC $<115 \mathrm{~mm}$ was classified as severe acute malnutrition, MUAC $=115-124 \mathrm{~mm}$ as moderate acute malnutrition and $M U A C \geq 125 \mathrm{~mm}$ as no malnutrition ${ }^{(19,20)}$. Verbal informed consent of the respondent was obtained prior to administration of the questionnaire.

Household survey questionnaires were administered by trained enumerators located in eastern Ukraine with 
experience in conducting household surveys. Enumerators were trained by Russian-speaking CDC staff on sampling procedures, questionnaire administration, interview techniques, telephone screening procedures to identify eligible households and MUAC measurement techniques. A standardization exercise on measuring MUAC in children included ten children aged 6-23 months who were ineligible for the survey. Technical error of measurement and bias were calculated for each enumerator to assess accuracy and precision of measurements ${ }^{(21)}$.

Data were entered in Epi Info version 7.1.5.0. Double data entry was performed and discrepancies were reconciled using the original paper form. All analyses were conducted using the statistical software package STATA version 13 and Microsoft ${ }^{\circledR}$ Excel 2013. WHO IYCF indicators were calculated according to the instructions in the WHO manual ${ }^{(18)}$. The dietary diversity indicator in the present study was measured using six food groups instead of the standard seven food groups used by WHO, by combining vitamin-A rich fruits and vegetables with other fruits and vegetables, as it was more appropriate to the Ukrainian context. Due to fewer food groups, the proportion of children 6-23 months of age receiving foods from three or more food groups (instead of the WHO standard four or more foods groups) was considered adequate minimum dietary diversity in the present study $^{(18)}$. Children's complementary feeding practices were assessed by calculating the proportions of the types of foods and liquids children consumed in the $24 \mathrm{~h}$ preceding the survey and the mean age at which various foods and liquids were introduced.

Using bivariate and multivariate logistic regression models, we assessed the association of potential risk factors with key IYCF indicators as the outcome variables in order to identify target populations for improvement of IYCF practices. Potential risk factors used as predictor variables were: child's age and sex, whether the child was born before or after displacement, maternal age and education level, number of children born to the mother, current location of the household, length of displacement, total number of children aged less than 2 years living in the household, sex of the head of household, place of permanent residence before displacement, whether the household was paying rent and current household employment. We assessed eight outcome variables, all key IYCF indicators: whether the child was ever breast-fed, early initiation of breast-feeding within an hour of birth, exclusive breast-feeding of infants aged less than 6 months, continued breast-feeding at 1 and 2 years of age, introduction of solid foods, bottle-feeding and minimum meal frequency. Each outcome variable was tested in bivariate analyses with each potential risk factor. Statistically significant risk factors at a $P \leq 0.05$ level were included in a multivariate logistic regression model to estimate OR and $95 \%$ CI. If no risk factors were found to be statistically significant in the bivariate analyses, a multivariate model was not constructed. Data presented in the results are from the multivariate models.

\section{Results}

The household survey was conducted between 8 June 2015 and 19 June 2015. A total of 2278 households were contacted by telephone and $770(33.8 \%)$ were eligible. Data were collected on 458 eligible households resulting in a response rate of $59.5 \%(458 / 770)$. Table 1 shows the eligibility, reasons for non-eligibility and response rate for eligible households among internally displaced households contacted via telephone for the survey.

There were 230, 130 and 117 children surveyed in Kharkiv, Dnipropetrovsk and Zaporizhia oblasts, respectively. Child, maternal and household characteristics are shown in Table 2. Among the 477 children, $51.8 \%$ were male and the mean age was 12.8 (sD 5.8) months. Of the 458 mothers surveyed, the mean age was 30.1 (SD 5.3) years, $59.6 \%$ had completed a minimum of a college degree and $43.0 \%$ only had one child. The majority of the 458 internally displaced households were located in the oblast centre (75.8\%). Most households (76.0\%) were responsible for paying rent for their current dwelling. Only forty-two households (9.2\%) had been displaced for less than 6 months, $289(63.1 \%)$ had been displaced for between 6 and 11 months, and 127 (27.7\%) had been displaced for 1 year or longer. Almost all households (94.3\%) had only one child aged less than 2 years living in the household. The mean number of people living in a household was 4.2 (SD 1.6).

Table 1 Eligibility, reasons for non-eligibility and response rate among internally displaced households residing in Kharkiv, Dnipropetrovsk and Zaporizhia oblasts, eastern Ukraine, contacted via telephone during June 2015

\begin{tabular}{|c|c|c|c|c|c|c|c|c|c|c|c|c|}
\hline \multirow[b]{3}{*}{ Oblast } & \multicolumn{7}{|c|}{ Ineligible households ( $N$ 1508) } & \multicolumn{5}{|c|}{ Eligible households ( $N 770$ ) } \\
\hline & \multicolumn{2}{|c|}{ Not reached by phone } & \multicolumn{2}{|c|}{ Moved } & \multicolumn{2}{|c|}{ Child aged $\geq 2$ years } & \multirow{2}{*}{$\frac{\text { Total ineligible }}{n}$} & \multicolumn{2}{|c|}{ Refused } & \multicolumn{2}{|c|}{ Consented } & \multirow{2}{*}{$\frac{\text { Total eligible }}{n}$} \\
\hline & $n$ & $\%$ & $n$ & $\%$ & $n$ & $\%$ & & $n$ & $\%$ & $n$ & $\%$ & \\
\hline Dnipropetrovsk (N 886) & 246 & $37 \cdot 3$ & 182 & $27 \cdot 6$ & 231 & $35 \cdot 1$ & 659 & 104 & $45 \cdot 8$ & 123 & $54 \cdot 2$ & 227 \\
\hline Zaporizhia $(N 409)$ & 98 & 37.1 & 84 & 31.8 & 82 & $31 \cdot 1$ & 264 & 32 & $22 \cdot 1$ & 113 & 77.9 & 145 \\
\hline Kharkiv ( $N 983$ ) & 198 & 33.9 & 199 & 34.0 & 188 & $32 \cdot 1$ & 585 & 176 & $44 \cdot 2$ & 222 & $55 \cdot 8$ & 398 \\
\hline Total $(N 2278)$ & 542 & $36 \cdot 0$ & 465 & 30.8 & 501 & $33 \cdot 2$ & 1508 & 312 & 40.5 & 458 & 59.5 & 770 \\
\hline
\end{tabular}


Table 2 Child, maternal and household characteristics among internally displaced persons residing in Kharkiv, Dnipropetrovsk and Zaporizhia oblasts, eastern Ukraine, June 2015

\begin{tabular}{|c|c|c|}
\hline Characteristic & $n$ & $\%$ \\
\hline \multicolumn{3}{|l|}{ Child (N 477) } \\
\hline Male & 247 & 51.8 \\
\hline \multicolumn{3}{|l|}{ Age (months) } \\
\hline $0-5$ & 66 & $13 \cdot 8$ \\
\hline $6-11$ & 163 & 34.2 \\
\hline $12-17$ & 152 & 31.9 \\
\hline $18-23$ & 96 & $20 \cdot 1$ \\
\hline \multicolumn{3}{|l|}{ Maternal ( $N$ 458) } \\
\hline \multicolumn{3}{|l|}{ Age (years) } \\
\hline$<25$ & 64 & 14.0 \\
\hline $25-29$ & 157 & 34.3 \\
\hline $30-34$ & 151 & 33.0 \\
\hline$\geq 35$ & 86 & $18 \cdot 8$ \\
\hline Completed higher education & 273 & 59.6 \\
\hline \multicolumn{3}{|l|}{ Total number of children } \\
\hline 1 & 197 & 43.0 \\
\hline$\geq 2$ & 261 & $57 \cdot 0$ \\
\hline \multicolumn{3}{|l|}{ Household ( $N 458)$} \\
\hline \multicolumn{3}{|l|}{ Household location } \\
\hline Oblast center & 347 & $75 \cdot 8$ \\
\hline Other city or village & 111 & 24.2 \\
\hline \multicolumn{3}{|l|}{ Living situation } \\
\hline Renting an apartment or house & 348 & $76 \cdot 0$ \\
\hline Living with relatives or friends (no fee) & 78 & $17 \cdot 0$ \\
\hline Collective centre (no fee) & 31 & 6.8 \\
\hline Other & 1 & 0.2 \\
\hline \multicolumn{3}{|l|}{ Oblast of origin } \\
\hline Donetsk & 289 & 63.1 \\
\hline Luhansk & 162 & 35.4 \\
\hline Other & 7 & 1.5 \\
\hline \multicolumn{3}{|l|}{ Length of displacement } \\
\hline$<6$ months & 42 & $9 \cdot 2$ \\
\hline $6-11$ months & 289 & 63.1 \\
\hline$\geq 12$ months & 127 & $27 \cdot 7$ \\
\hline \multicolumn{3}{|c|}{ Total no. of children aged $<2$ years in household } \\
\hline 1 & 432 & 94.3 \\
\hline 2 & 26 & $5 \cdot 7$ \\
\hline \multicolumn{3}{|l|}{ Head of household } \\
\hline Male & 229 & $50 \cdot 0$ \\
\hline Female & 223 & $48 \cdot 7$ \\
\hline Don’t know & 6 & 1.3 \\
\hline Resident of household earning money & 245 & 53.5 \\
\hline
\end{tabular}

\section{Ever breast-fed}

Table 3 shows the prevalence of key WHO IYCF indicators in our survey population. The majority of children were ever breast-fed (93.3\%; $95 \%$ CI 90.7, 95.2\%), which was similar among children born during the conflict in the 11 months preceding the survey $(93.9 \%$; $95 \%$ CI 90.0 , 96.6\%) and those born before the conflict began in the 12-23 months preceding the survey (92.7\%; 95\% CI 88.8, 95.6\%). Among infants aged $<6$ months, $7 \cdot 6$ (95\% CI 2.5, $16.8) \%$ were never breast-fed. Risk factors significantly associated with key WHO IYCF indicators in multivariate analyses are shown in Table 4. Older mothers were less likely to have ever breast-fed their child than younger mothers (OR $=0.92 ; 95 \%$ CI 0.86, 0.98). Mothers who had completed higher education had $6 \cdot 10$ (95\% CI 2.41, 15.42) times greater odds of having ever breast-fed their child than mothers who had not completed higher education.

\section{Early breast-feeding initiation}

Only 63.7 (95\% CI 59.3, 67.9)\% of mothers initiated breast-feeding within the first hour of birth. The prevalence was slightly lower among children born during the conflict $(61.1 \% ; 95 \%$ CI $54.5,67.5 \%)$ than before the conflict began $(66 \cdot 1 \%$; $95 \%$ CI 60.0, $72 \cdot 0 \%)$, although this was not significant (Table 3). Mothers living with two children less than 2 years of age in the household had lower odds of initiating breast-feeding within the first hour of birth compared with mothers living with one child aged less than 2 years in the household ( $\mathrm{OR}=0.29 ; 95 \% \mathrm{CI}$ $0 \cdot 13,0 \cdot 67$; Table 4). Mothers displaced from Luhansk oblast were less likely to initiate breast-feeding within the first hour of birth than mothers displaced from Donetsk oblast (OR $=0.63 ; 95 \%$ CI $0.42,0.94)$, with $58.6 \%$ of mothers displaced from Luhansk and $68.2 \%$ of mothers displaced from Donetsk initiating breast-feeding within the first hour of birth (Table 4).

\section{Exclusive and continued breast-feeding}

Exclusive breast-feeding of infants aged less than 6 months was low (25.8\%; $95 \%$ CI 15.8, 38.0\%; Table 3). Of those infants aged $<6$ months who were ever breast-fed, $19 \cdot 7$ (95\% CI 10.6, 31.8) \% were not breast-fed in the day preceding the survey. Younger infants in the less than 6 months age group had a greater odds of being exclusively breast-fed than older infants less than 6 months of age $(\mathrm{OR}=0.54 ; 95 \%$ CI $0.32,0.91)$. Exclusive breastfeeding of infants aged less than 6 months was less prevalent in households where a female was considered the head of the household $(7 \cdot 1 \%)$ than in households where a male was considered the head of the household (38.2\%; $\mathrm{OR}=0.11 ; 95 \%$ CI $0.02,0.62$; Table 4). About half of children (53.5\%; $95 \%$ CI 43.2, 63.6\%) were continuing to be breast-fed at 1 year of age and 20.6 (95\% CI 11.5 , $32.7) \%$ of children were continuing to be breast-fed at 2 years of age (Table 3). Older children in the 20-23 month age group had lower odds of being breast-fed at 2 years of age than younger children aged 20-23 months $(\mathrm{OR}=0 \cdot 38 ; 95 \%$ CI 0.19, 0.77; Table 4).

\section{Bottle-feeding}

A high proportion of children aged less than 2 years (68.1\%; 95\% CI 63.7, 72.3\%) were bottle-fed; 65.1 (95\% CI $52 \cdot 4,76 \cdot 5) \%$ of infants aged less than 6 months were bottle-fed (Table 3). Mothers who had completed higher education were less likely to bottle-feed their infants than mothers who had not completed higher education $(63.7$ and $73.0 \%$ bottle-feeding, respectively; $\mathrm{OR}=0.61 ; 95 \% \mathrm{CI}$ $0 \cdot 40,0.92)$. Younger children aged less than 2 years had higher odds of being bottle-fed than older children in this age group (OR=0.94; 95\% CI 0.90, 0.97; Table 4).

\section{Complementary feeding}

Almost all infants aged 6-8 months were receiving solid or semi-solid foods (98.6\%; $95 \%$ CI 88.5, 99.9\%) and nearly 
Table 3 Key WHO indicators of infant and young child feeding for internally displaced children aged <2 years residing in Kharkiv, Dnipropetrovsk and Zaporizhia oblasts, eastern Ukraine, June 2015

\begin{tabular}{|c|c|c|c|c|}
\hline Indicator & $n$ & $N$ & $\%$ & $95 \% \mathrm{Cl}$ \\
\hline \multicolumn{5}{|l|}{ Ever breast-fed } \\
\hline Children born 11 months preceding survey & 215 & 229 & 93.9 & $90 \cdot 0,96 \cdot 6$ \\
\hline Children born 12-23 months preceding survey & 230 & 248 & 92.7 & $88 \cdot 8,95 \cdot 6$ \\
\hline Total & 445 & 477 & $93 \cdot 3$ & $90 \cdot 7,95 \cdot 2$ \\
\hline \multicolumn{5}{|l|}{ Early initiation of breast-feeding (within $1 \mathrm{~h}$ of birth) } \\
\hline Children born 11 months preceding survey & 140 & 229 & $61 \cdot 1$ & $54.5,67.5$ \\
\hline Children born 12-23 months preceding survey & 164 & 248 & $66 \cdot 1$ & $60 \cdot 0,72 \cdot 0$ \\
\hline Total & 304 & 477 & 63.7 & $59 \cdot 3,67 \cdot 9$ \\
\hline \multicolumn{5}{|l|}{ Exclusive breast-feeding $<6$ months } \\
\hline $0-1$ month & 3 & 5 & $60 \cdot 0$ & $14 \cdot 7,94.7$ \\
\hline $2-3$ months & 9 & 23 & $39 \cdot 1$ & $19 \cdot 7,61 \cdot 5$ \\
\hline $4-5$ months & 5 & 38 & $13 \cdot 2$ & $4 \cdot 4,28 \cdot 1$ \\
\hline Total & 17 & 66 & $25 \cdot 8$ & $15 \cdot 8,38.0$ \\
\hline Continued breast-feeding at 1 year ( $N=$ children aged $12-15$ months) & 53 & 99 & 53.5 & $43 \cdot 2,63 \cdot 6$ \\
\hline Continued breast-feeding at 2 years ( $N=$ children aged $20-23$ months) & 13 & 63 & $20 \cdot 6$ & $11.5,32 \cdot 7$ \\
\hline Introduction of solid, semi-solid or soft foods ( $N=$ infants aged $6-8$ months) & 71 & 72 & $98 \cdot 6$ & $88.5,99.9$ \\
\hline \multicolumn{5}{|l|}{ Bottle feeding } \\
\hline $0-5$ months & 43 & 66 & $65 \cdot 1$ & $52 \cdot 4,76 \cdot 5$ \\
\hline $6-11$ months & 132 & 163 & $81 \cdot 0$ & $74 \cdot 1,86 \cdot 7$ \\
\hline $12-23$ months & 150 & 248 & 60.5 & $54 \cdot 1,66 \cdot 6$ \\
\hline Total & 325 & 477 & $68 \cdot 1$ & $63 \cdot 7,72 \cdot 3$ \\
\hline \multicolumn{5}{|l|}{ Minimum meal frequency $*$ ( $N=$ children aged $6-23$ months $)$} \\
\hline Breast-feeding & 179 & 186 & $96 \cdot 2$ & $92.4,98.5$ \\
\hline Non-breast-feeding & 222 & 225 & $98 \cdot 7$ & $96 \cdot 1,99 \cdot 7$ \\
\hline Total & 401 & 411 & $97 \cdot 6$ & $95 \cdot 6,98.8$ \\
\hline
\end{tabular}

*Breast-fed children 6-23 months who received solid, semi-solid or soft foods the minimum number of times (two times for infants 6-8 months and three times for children 9-23 months) or more per day and non-breast-fed children 6-23 months who received solid, semi-solid or soft foods or milk feeds four times or more per day.

Table 4 Risk factors associated in multivariate analyses with key WHO indicators of infant and young child feeding for internally displaced children aged $<2$ years residing in Kharkiv, Dnipropetrovsk and Zaporizhia oblasts, eastern Ukraine, June 2015*

\begin{tabular}{|c|c|c|c|c|c|}
\hline Outcome & $N$ & Predictor & OR & $95 \% \mathrm{Cl}$ & $P$ value \\
\hline \multirow[t]{2}{*}{ Ever breast-fed } & 477 & Mother's age (years) & 0.92 & $0.86,0.98$ & 0.017 \\
\hline & & Mother completed higher education $\dagger$ & $6 \cdot 10$ & $2 \cdot 41,15 \cdot 42$ & $<0.001$ \\
\hline \multirow[t]{2}{*}{ Early initiation of breast-feeding (within $1 \mathrm{~h}$ of birth) } & 477 & Two children aged $<2$ years in household $\neq$ & 0.29 & $0.13,0.67$ & 0.004 \\
\hline & & Displaced from Luhansk oblast§ & 0.63 & $0.42,0.94$ & 0.025 \\
\hline \multirow[t]{2}{*}{ Exclusive breast-feeding $<6$ months } & 66 & Female head of household $\|$ & 0.11 & $0.02,0.62$ & 0.012 \\
\hline & & Child's age (months) & 0.54 & $0.32,0.91$ & 0.021 \\
\hline $\begin{array}{l}\text { Continued breast-feeding at } 2 \text { years }(N=\text { children } \\
\text { aged } 20-23 \text { months) }\end{array}$ & 63 & Child's age (months) & 0.38 & $0.19,0.77$ & 0.006 \\
\hline \multirow[t]{2}{*}{ Bottle feeding } & 477 & Child's age (months) & 0.94 & $0.90,0.97$ & $<0.001$ \\
\hline & & Mother completed higher education† & 0.61 & $0.40,0.92$ & 0.018 \\
\hline
\end{tabular}

*No risk factors tested were significantly associated with continued breast-feeding at 1 year, introduction of solid, semi-solid or soft foods, or minimum meal frequency in multivariate models.

†Referent: mother did not complete higher education.

†Referent: one child aged $<2$ years in household.

§Referent: displaced from Donetsk oblast.

||Referent: male head of household.

all children aged 6-23 months met the minimum meal frequency $(97 \cdot 6 \%$; $95 \%$ CI 95.6, 98.8\%). The prevalence of children meeting the requirements for minimum meal frequency was similar among those children breastfeeding $(96.2 \%$; 95\% CI 92.4, 98.5\%) and those not breast-feeding (98.7\%; $95 \%$ CI 96.1, 99.7\%; Table 3). Most children aged 6-23 months (93.2\%; 95\% CI 90.3, 95.4\%) were given foods from three or more food groups and 84.7 (95\% CI 80.8, 88.0)\% received Fe-rich foods (infant formula, meat and fish, and/or commercial infant meat purée) on the day preceding the survey.
The proportion of internally displaced children who received various foods and liquids during the day preceding the survey is shown in Fig. 1. Bread or pasta were the foods given to the highest proportion of children aged 6 months or older in the day preceding the survey. A high proportion of children in older age groups ( $\geq 6$ months) were also given fruit, commercial infant porridge (instant porridge that is marketed to infants and young children) and homemade porridges (prepared from buckwheat, oatmeal, rice, semolina and other grains), and meat and fish. Commercial infant porridge was given to a higher 


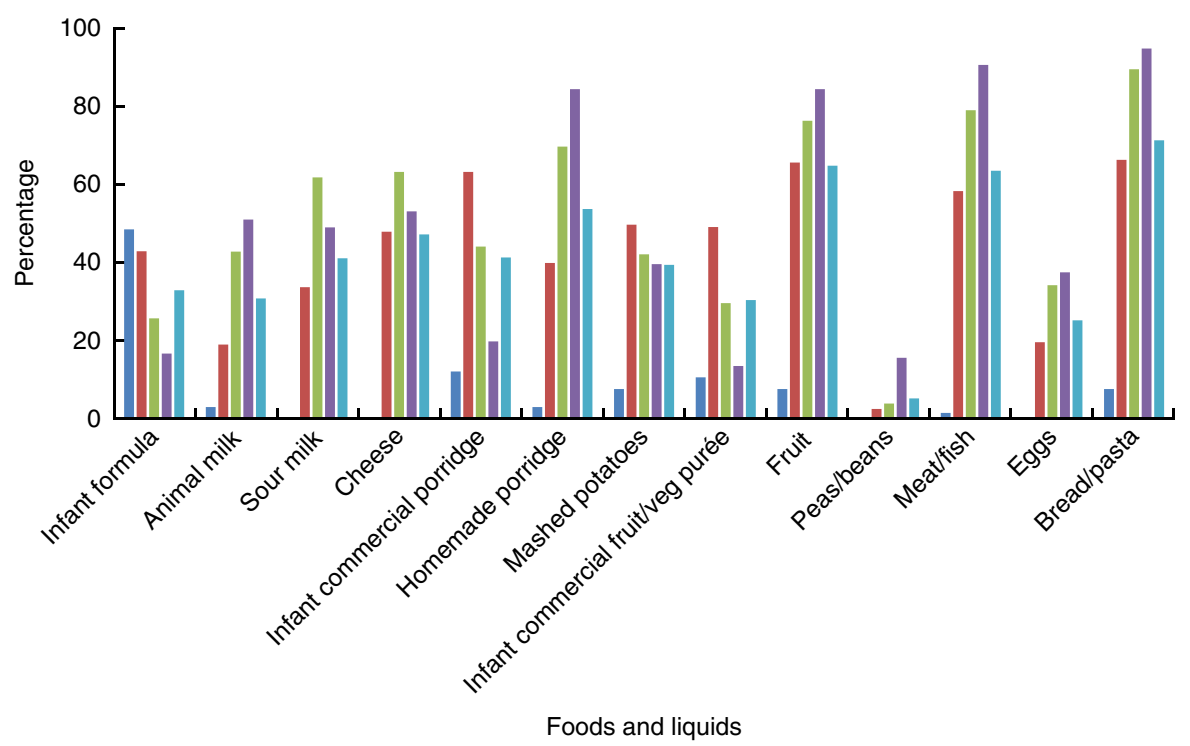

Fig. 1 (colour online) Proportion given foods and liquids in the $24 \mathrm{~h}$ preceding the survey, by age group ( $\square$, $0-5$ months; $\square$, 6-11 months; $\square, 12-17$ months; $\square, 18-23$ months; $\square$, total), among internally displaced children aged $<2$ years residing in Kharkiv, Dnipropetrovsk and Zaporizhia oblasts, eastern Ukraine, June 2015

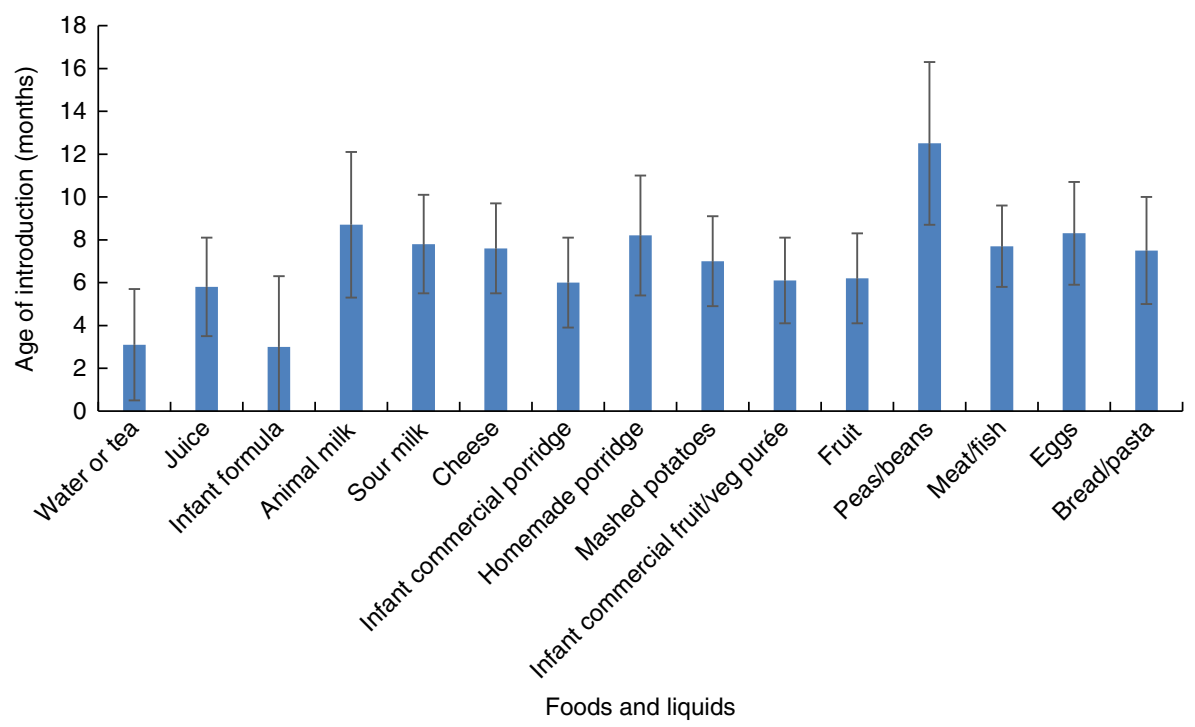

Fig. 2 Mean of age of introduction of foods and liquids, with standard deviation represented by vertical bars, to internally displaced children aged $<2$ years residing in Kharkiv, Dnipropetrovsk and Zaporizhia oblasts, eastern Ukraine, June 2015

proportion of infants in the 6-11 month age group compared with homemade porridges, which were more commonly given to children older than 1 year of age. Peas and beans were the least frequently consumed food group in all age groups.

The mean age of introduction of foods and liquids among children who had already been introduced to those foods or liquids at the time of the survey is shown in Fig. 2. The mean age of water or tea and infant formula introduction was $3 \cdot 1$ (SD 2.6) and 3.0 (SD 2.6) months, respectively. Water was given to the majority of infants aged less than 6 months who were not exclusively breast-fed $(85.7 \%$; $95 \%$ CI 72.8 ,
$94 \cdot 1 \%)$. Nearly one-fifth (18.2\%; $95 \%$ CI $9 \cdot 7,29 \cdot 6 \%)$ of infants aged less than 6 months received soft, semi-solid or solid foods on the day preceding the survey. Infant commercial porridges, commercial infant fruit and vegetable purées, and whole fruits were the complementary foods with the lowest mean age of introduction (about 6 months of age) and the most common complementary foods given to infants aged less than 6 months.

\section{Breast-feeding discontinuation}

The primary reasons for breast-feeding discontinuation reported by mothers who had stopped breast-feeding 
Table 5 Reasons for breast-feeding discontinuation (among those who discontinued breast-feeding prior to survey administration) reported by internally displaced mothers with children aged $<2$ years residing in Kharkiv, Dnipropetrovsk and Zaporizhia oblasts, eastern Ukraine, June 2015

\begin{tabular}{|c|c|c|c|c|c|c|}
\hline \multirow[b]{2}{*}{ Primary reason for breast-feeding discontinuation } & \multicolumn{3}{|c|}{$\begin{array}{l}\text { Breast-feeding discontinuation } \\
\text { at }<6 \text { months ( } N 105)\end{array}$} & \multicolumn{3}{|c|}{$\begin{array}{l}\text { Breast-feeding discontinuation } \\
\text { at } 6-23 \text { months ( } N 105)\end{array}$} \\
\hline & $n$ & $\%$ & $95 \% \mathrm{Cl}$ & $n$ & $\%$ & $95 \% \mathrm{Cl}$ \\
\hline Conflict-related stress & 48 & $45 \cdot 7$ & $36 \cdot 0,55 \cdot 7$ & 15 & $14 \cdot 3$ & $8 \cdot 2,22 \cdot 4$ \\
\hline Problems of attachment to breast & 10 & 9.5 & $4 \cdot 6,16 \cdot 8$ & 13 & $12 \cdot 4$ & $6 \cdot 8,20 \cdot 2$ \\
\hline Not enough food for mother & 10 & 9.5 & $4 \cdot 6,16 \cdot 8$ & 4 & $3 \cdot 8$ & $1.0,9.5$ \\
\hline Stress unrelated to conflict & 3 & 2.9 & $0.6,8 \cdot 1$ & 4 & $3 \cdot 8$ & $1 \cdot 0,9 \cdot 5$ \\
\hline Use of bottle for feeding & 1 & 1.0 & $0.2,5 \cdot 2$ & 3 & $2 \cdot 9$ & $0.6,8.1$ \\
\hline Work schedule & 0 & 0.0 & - & 1 & 0.9 & $0.2,5 \cdot 2$ \\
\hline Other & 29 & $27 \cdot 6$ & $19 \cdot 3,37 \cdot 2$ & 60 & $57 \cdot 1$ & $47 \cdot 1,66 \cdot 8$ \\
\hline Don't know & 4 & 3.8 & $1 \cdot 0,9.5$ & 5 & 4.8 & $1 \cdot 6,10 \cdot 8$ \\
\hline
\end{tabular}

prior to survey administration are shown in Table 5. Stress related to the conflict was a primary reason reported by mothers for breast-feeding discontinuation. Mothers who discontinued breast-feeding when their infants were aged less than 6 months were more likely to list stress related to the conflict as the primary reason they discontinued breast-feeding $(45.7 \%)$ compared with mothers who discontinued breast-feeding when their children were aged 6-23 months (14.3\%; $P<0.0001)$. When mothers were asked their opinions on when it is appropriate to stop breast-feeding, almost half of all mothers (46.9\%; $95 \%$ CI $42.3,51.6 \%$ ) believed they should not breast-feed beyond 12 months of age. Only $29 \cdot 5$ (95\% CI 25.3, 33.9)\% of mothers believed they should continue breast-feeding until 2 years of age and beyond.

\section{Acute malnutrition}

MUAC was measured in 411 children aged 6-23 months. Mean MUAC was 159.6 (SD 12.1) mm. No child aged 6-23 months had MUAC less than $115 \mathrm{~mm}$ and only two children in this age group $(0.5 \%$; $95 \%$ CI $0 \cdot 1,1 \cdot 7 \%)$ were moderately acutely malnourished (had MUAC between $115 \mathrm{~mm}$ and $125 \mathrm{~mm}$ ).

\section{Humanitarian assistance}

Four hundred and forty-seven of the 458 (97.6\%) households surveyed had received some type of humanitarian assistance from non-government sources. The majority of households $(87 \cdot 1 \% ; 95 \%$ CI $73 \cdot 1,81 \cdot 0 \%)$ received general food assistance. Over two-thirds (70.5\%; $95 \%$ CI 66.1, $74.7 \%$ ) of households received baby food assistance. However, only 14.8 (95\% CI 11.7, 18.4)\% of households received baby food assistance more than three times and the mean time since last receiving baby food assistance was $2 \cdot 8$ (SD 2.6) months preceding the survey. The most common items received in the most recent baby food assistance package were commercial infant porridge $(56.3 \%)$, commercial infant fruit or vegetable purée (49.2\%) and infant formula (44.3\%).

\section{Discussion}

Our study of IDP in eastern Ukraine highlighted several problematic issues related to IYCF practices which need improvement, including a low prevalence of exclusive breast-feeding until 6 months of age, a low prevalence of continued breast-feeding until 2 years of age, introduction of fluids before 6 months of age and a high prevalence of bottle-feeding. These issues were similar to those identified in pre-conflict surveys; however, our study found that stress related to the conflict was a major reason that mothers discontinued breast-feeding ${ }^{(14)}$. Our study also found that, overall, complementary feeding in children aged 6 months or older in this population was adequate, as almost all children in this age group were receiving soft, semi-solid or solid foods and meeting their minimum meal frequency. In addition, most children in this age group were receiving Fe-rich foods and meeting the requirements for minimum dietary diversity.

The majority of women had ever breast-fed their child (93.3\%). However, the prevalence of other recommended breast-feeding practices, including exclusive breastfeeding in infants aged less than 6 months, was low. Only about one-quarter of mothers with infants less than 6 months of age were exclusively breast-feeding. These estimates are similar to the MICS 2012 survey data for eastern Ukraine, which reported $96.7 \%$ of children ever breast-fed and $21.3 \%$ of infants less than 6 months of age exclusively breast-fed ${ }^{(14)}$. Mothers were less likely to exclusively breast-feed in households where a woman was considered the head of the household, which was similar to findings by Andersson et al. during the Bosnian conflict $^{(22)}$. These women may have more responsibilities and less time to breast-feed. Similar to our study, Andersson et al. found that the proportion of infants who were ever breast-fed was similar before and during the Bosnian conflict ${ }^{(22)}$.

Among infants aged less than 6 months who were not exclusively breast-fed, water, tea and infant formula were the liquids most commonly given; this likely reflects 
common beliefs in Ukraine that infants need water when the mother feels thirsty and it is warm outside. In addition, infant feeding behaviors of mothers were influenced by their social networks (family and friends) ${ }^{(23)}$. Some mothers introduced complementary foods before 6 months of age, most commonly commercial infant porridges and commercial infant fruit and vegetable purées. Previous studies have also found women having difficulties adhering to the WHO guidelines of not introducing complementary foods before 6 months of age, often due to outside influences and prior beliefs $^{(24-26)}$. A study in Australia found that first-time mothers believe that early introduction of complementary foods will help with weight gain and sleeping patterns ${ }^{(26)}$. In addition, studies in Australia and the UK found that peer groups influenced a mother's decision on the timing of complementary food introduction ${ }^{(24,25)}$.

Contrary to WHO and UNICEF recommendations, a high proportion of mothers (36\%) did not initiate breastfeeding during the first hour after birth. This was similar to pre-conflict data, where $39 \%$ of Ukrainian mothers did not initiate breast-feeding within the first hour of birth and better than in Belarus, where $47 \%$ of women did not initiate breast-feeding during their child's first hour of life ${ }^{(13,14)}$. Infants who are not breast-fed within the first hour of birth are less likely to receive colostrum, which contains many protective factors such as antibodies and other immune components ${ }^{(27)}$. In addition, infants fed colostrum have lower neonatal and post-neonatal death rates ${ }^{\text {(28) }}$. Mothers displaced from Luhansk oblast were less likely to initiate breast-feeding within the first hour of birth than mothers displaced from Donetsk oblast. The reasons for this are unclear; however, if the mothers had given birth prior to displacement, it is possible that health facilities in Donetsk were more supportive of early initiation of breast-feeding than health facilities in Luhansk, which could be an area for targeted IYCF interventions.

A high proportion of children surveyed were fed by a bottle on the day preceding the survey. Bottle-feeding may reduce the mother's breast milk production and shorten the time to breast-feeding discontinuation, possibly due to nipple confusion ${ }^{(29-33)}$. Nipple confusion is defined in younger infants as the difficulty for a neonate to establish the necessary latching technique and sucking pattern to extract milk from the breast after exposure to an artificial nipple; and in older infants who have established breast-feeding as the refusal of the breast in preference for the bottle ${ }^{(33,34)}$. Feeding infants fluids with a cup or spoon instead of a bottle may help to avoid early breast-feeding discontinuation due to nipple confusion and is a better way to provide supplemental feeding to infants ${ }^{(33,35)}$. Similar to previous studies, more educated mothers were less likely to bottle-feed their infants than mothers with less education ${ }^{(36,37)}$. These less educated mothers could be a group targeted during IYCF education and counselling interventions.

Fifty-four per cent of mothers were continuing to breastfeed when their child was 1 year of age and about one-fifth were breast-feeding their child at 2 years of age. Almost half of all mothers surveyed believed that mothers should not breast-feed beyond 12 months, despite the WHO and UNICEF recommendations that mothers should breast-feed their children until 2 years of age and beyond ${ }^{(11)}$. Stress related to the conflict was the most common perceived reason mothers reported discontinuing breast-feeding before their infant was 6 months old and it was a common reason for breast-feeding discontinuation for all mothers who reported stopping prior to survey administration. Previous studies have found stress to be associated with shorter durations of both continued and exclusive breast-feeding. Dozier et al. found financial stress to be associated with earlier breast-feeding discontinuation and traumatic stress to be associated with earlier exclusive breast-feeding discontinuation $^{(38)}$. In addition, a study in Australia by Li et al. also showed early breast-feeding discontinuation to be significantly associated with stressful life events ${ }^{(39)}$.

Almost all children aged 6-23 months were receiving solid or semi-solid foods and minimum meal frequency was met by almost all children. Quality of complementary foods was also adequate, as most children were eating a sufficient variety. The majority of children 6-23 months of age $(93 \%)$ were given foods from three or more food groups in the $24 \mathrm{~h}$ preceding the survey and $85 \%$ received Fe-rich foods. Children aged 12-23 months received a greater variety of foods than infants aged 6-11 months. In addition, no children aged 6-23 months were identified with severe acute malnutrition (MUAC $<115 \mathrm{~mm}$ ) and only two children aged 6-23 months were identified with moderate acute malnutrition (MUAC $=115-124 \mathrm{~mm}$ ).

The present study is subject to several potential limitations. First, we surveyed only those households included in the registration lists from humanitarian aid agencies, with a working telephone number and available during the survey period. Unregistered households and those without a working telephone number may be receiving less humanitarian aid and/or be of lower socio-economic status, which could have an impact on their IYCF practices. Second, the survey had a high level of non-response among eligible households, likely due to personal safety concerns related to the conflict. In addition, due to security issues, households located in oblasts within the conflict zone were not included in the survey. These households may have lower food security than households bordering the conflict zone. In addition, mothers in these areas may also experience greater stress, which may make them more likely to discontinue breast-feeding at earlier ages. Finally, there is the possibility of recall bias in self-reported data.

\section{Conclusions}

In our study of IDP in eastern Ukraine, we identified multiple suboptimal IYCF practices, including non-exclusive breast-feeding until 6 months of age, introduction of fluids 
before 6 months of age, bottle-feeding and discontinuing breast-feeding before 2 years of age. These were similar to those identified in a broader population in Ukraine prior to the conflict. Overall, complementary feeding in children aged 6 months or older in this population was adequate and most children in this age group were receiving Fe-rich foods and meeting the requirements for minimum dietary diversity. Our study also demonstrated that stress related to the conflict is a primary reason for breast-feeding discontinuation in this population. In order to mitigate the effects of conflict and improve child health, humanitarian action focused on helping mothers cope with stress related to conflict and displacement by supporting maternal mental health and psychosocial support programmes is needed. In addition, humanitarian action should support and encourage women to adhere to recommended IYCF practices if possible and support women for artificial or complementary feeding when adherence is not feasible.

\section{Acknowledgements}

Avknowledgements: The athors would like to acknowledge UNICEF Ukraine, InMind and New Image Marketing Group for their support in conducting this study. Financial support: The field data collection for this study was funded by UNICEF Ukraine. No funding was provided to the CDC. Conflict of interest: None. Authorship: Both A.S. and O.O.B. participated in formulating the research questions, designing the study, collecting the data, analysing the data, interpreting the data and drafting the manuscript. A.S. and O.O.B. read and approved the final manuscript. Both authors had full access to all data and take responsibility for the integrity of the data and the accuracy of the data analysis. Ethics of human subject participation: This study was determined to be nonresearch by the Institutional Review Board of the CDC as the primary intent was humanitarian needs assessment to inform specific public health programme activity. Verbal informed consent was obtained from all participants. Verbal consent was witnessed and recorded.

\section{References}

1. Black RE, Allen LH, Bhutta ZA et al. (2008) Maternal and child undernutrition: global and regional exposures and health consequences. Lancet 371, 243-260.

2. Cushing AH, Samet JM, Lambert WE et al. (1998) Breastfeeding reduces risk of respiratory illness in infants. $\mathrm{Am} \mathrm{J}$ Epidemiol 147, 863-870.

3. Heinig MJ \& Dewey KG (1996) Health advantages of breast feeding for infants: a critical review. Nutr Res Rev $\mathbf{9}$, 89-110.

4. Jones G, Steketee RW, Black RE et al. (2003) How many child deaths can we prevent this year? Lancet 362, 65-71.

5. Debes AK, Kohli A, Walker N et al. (2013) Time to initiation of breastfeeding and neonatal mortality and morbidity: a systematic review. BMC Public Health 13, Suppl. 3, S19.
6. Edmond KM, Zandoh C, Quigley MA et al. (2006) Delayed breastfeeding initiation increases risk of neonatal mortality. Pediatrics 117, e380-e386.

7. Mullany LC, Katz J, Li YM et al. (2008) Breast-feeding patterns, time to initiation, and mortality risk among newborns in southern Nepal. J Nutr 138, 599-603.

8. Chen A \& Rogan WJ (2004) Breastfeeding and the risk of postneonatal death in the United States. Pediatrics 113, e435-e439.

9. McVea KL, Turner PD \& Peppler DK (2000) The role of breastfeeding in sudden infant death syndrome. J Hum Lact 16, $13-20$.

10. Schellscheidt J, Ott A \& Jorch G (1997) Epidemiological features of sudden infant death after a German intervention campaign in 1992. Eur J Pediatr 156, 655-660.

11. World Health Organization (2002) Infant and Young Child Nutrition; Global Strategy on Infant and Young Child Feeding. Geneva: WHO.

12. Centers for Disease Control and Prevention (2015) Hospital Actions Affect Breastfeeding. CDC Vitalsigns. Atlanta, GA: CDC.

13. National Statisitcal Committee of the Republic of Belarus \& UNICEF (2013) Multiple Indicator Cluster Survey of the Situation of Children and Women in the Republic of Belarus (МИКС4), 2012. Final Report. Minsk: National Statistical Committee of the Republic of Belarus and UNICEF.

14. State Statistics Service \& Ukrainian Center for Social Reforms (2013) Ukraine Multiple Indicator Cluster Survey 2012, Final Report. Kiev: State Statistics Committee and the Ukrainian Center for Social Reforms.

15. United Nations Office for the Coordination of Humanitarian Affairs (2015) Ukraine Situation Update 27 June-10 July 2015. http://www.reliefweb.int/sites/reliefweb.int/files/ resources/ocha_ukraine_situation_update_27_june_-_10_july_ 2015.pdf (accessed May 2016).

16. The Sphere Project (2004) Sphere Project Humanitarian Charter and Minimum Standards of Disaster Response (revised edition). Oxford: Oxfam GB.

17. Presley SM, Rainwater TR, Austin GP et al. (2006) Assessment of pathogens and toxicants in New Orleans, LA following Hurricane Katrina. Environ Sci Technol 40, 468-474.

18. World Health Organization (2008) Indicators for Assessing Infant and Young Child Feeding Practices. Geneva: WHO.

19. Emergency Nutrition Network, Global Nutrition Cluster (2011) The Harmonised Training Package (HTP): Resource Material for Training on Nutrition in Emergencies, Version 2. Oxford: Emergency Nutrition Network.

20. World Health Organization (1995) Physical Status: The Use and Interpretation of Anthropometry. Report of a WHO Expert Committee. WHO Technical Report Series no. 854. Geneva: WHO.

21. Ulijaszek SJ \& Kerr DA (1999) Anthropometric measurement error and the assessment of nutritional status. Br J Nutr $\mathbf{8 2}$, $165-177$.

22. Andersson N, Paredes-Solis S, Legorreta-Soberanis J et al. (2010) Breast-feeding in a complex emergency: four linked cross-sectional studies during the Bosnian conflict. Public Health Nutr 13, 2097-2104

23. Summers A \& Bilukha O (2015) Emergency Infant and Young Child Feeding Assessment among Internally Displaced Persons - Kharkiv, Dnipropetrovsk, and Zaporizhia, Ukraine, Final Report. Kiev: Centers for Disease Control and Prevention and UNICEF.

24. Arden MA (2010) Conflicting influences on UK mothers' decisions to introduce solid foods to their infants. Matern Child Nutr 6, 159-173.

25. Cameron AJ, Hesketh K, Ball K et al. (2010) Influence of peers on breastfeeding discontinuation among new parents: the Melbourne InFANT Program. Pediatrics 126, e601-e607. 
26. Walsh A, Kearney L \& Dennis N (2015) Factors influencing first-time mothers' introduction of complementary foods: a qualitative exploration. BMC Public Health 15, 939.

27. Goldman AS (2007) The immune system in human milk and the developing infant. Breastfeed Med 2, 195-204.

28. Singh K \& Srivastava P (1992) The effect of colostrum on infant mortality: urban rural differentials. Health Popul Perspect Issues 15, 94-100.

29. Kliethermes PA, Cross ML, Lanese MG et al. (1999) Transitioning preterm infants with nasogastric tube supplementation: increased likelihood of breastfeeding. $J$ Obstet Gynecol Neonatal Nurs 28, 264-273.

30. Righard L (1998) Are breastfeeding problems related to incorrect breastfeeding technique and the use of pacifiers and bottles? Birth 25, 40-44.

31. Camurdan AD, Ilhan MN, Beyazova U et al. (2008) How to achieve long-term breast-feeding: factors associated with early discontinuation. Public Health Nutr 11, 1173-1179.

32. Marandi A, Afzali HM \& Hossaini AF (1993) The reasons for early weaning among mothers in Teheran. Bull World Health Organ 71, 561-569.
33. Zimmerman E \& Thompson K (2015) Clarifying nipple confusion. J Perinatol 35, 895-899.

34. Neifert M, Lawrence R \& Seacat J (1995) Nipple confusion: toward a formal definition. J Pediatr 126, issue 6, S125-S129.

35. Howard CR, Howard FM, Lanphear B et al. (2003) Randomized clinical trial of pacifier use and bottle-feeding or cupfeeding and their effect on breastfeeding. Pediatrics 111, 511-518.

36. Shamim S, Jamalvi SW \& Naz F (2006) Determinants of bottle use amongst economically disadvantaged mothers. J Ayub Med Coll Abbottabad 18, 48-51.

37. Machado MC, Assis KF, Oliveira Fde C et al. (2014) Determinants of the exclusive breastfeeding abandonment: psychosocial factors. Rev Saude Publica 48, 985-994.

38. Dozier AM, Nelson A \& Brownell E (2012) The relationship between life stress and breastfeeding outcomes among low-income mothers. Adv Prev Med 2012, 902487.

39. Li J, Kendall GE, Henderson $\mathrm{S}$ et al. (2008) Maternal psychosocial well-being in pregnancy and breastfeeding duration. Acta Paediatr 97, 221-225. 